\title{
Healthy Aging in Cities
}

\section{Andrew Quinn}

In the coming decades, the global population will urbanize and age at high rates. Today, half of the world's populations lives in cities. ${ }^{1}$ By 2030 , that proportion will rise to $60 \%$, and urbanization will occur most greatly in developing countries. ${ }^{1}$ At the same time, the world's population aged 60 and over will double from $11 \%$ to $22 \%$ by $2050,{ }^{2}$ and that growth will be concentrated in urban areas in less developed countries. ${ }^{3}$ All of these trends challenge public health workers, doctors, researchers, and urban planners to ensure healthy livable cities for older people.

In response to those trends, the WHO has released a guide, Global Age-Friendly Cities, aimed at urban planners, that details the features of age friendly cities: transportation, housing, social participation, respect and social inclusion, civic participation and employment, communication and information, community support and health services, and outdoor spaces and buildings. ${ }^{1,4}$ In developing the guide, the WHO conducted 158 focus groups with people aged 60 and over in 35 international cities to determine the age-friendly features of their city, the problems they encounter, and what is missing in the city that could potentially benefit the health or quality of life of the aging population. In addition, the WHO hosted focus groups with a number of caregivers and service providers to complement the information provided by older people. The guide concludes that age-friendly cities must provide adequate and accessible housing, transportation services and infrastructures linked to social, civic, economic, and health services and opportunities, inclusion of older people in notable social and civic positions, and open information distribution.

The American Association of Retired Persons (AARP) defines a livable community, in much the same vein, as "one that has affordable and appropriate housing, supportive community features and services, and adequate mobility options, which, together facilitate personal independence and the engagement of residents in civic and social life". 5 Large, dense cities, especially in the developed world, offer more mass transit facilities and ADA paratransit than rural areas. Older residents in rural and suburban areas must rely on cars to reach almost any destination, and if unable to drive, their mobility is severely limited. At the same time, cities offer more social and civic opportunities, such as entertainment, neighborhood and community organizations, and volunteer charities, which, as the AARP report notes, are all related to successful aging. ${ }^{5}$ Such social engagement has even been linked to improvements in physical health. ${ }^{6}$ Research has also shown that dense urban areas with mixed uses and good pedestrian sidewalks are associated with increased walking among older residents, allowing them to engage their communities and maintain their physical health. ${ }^{7-10}$ All of these benefits tend to be concentrated in naturally occurring retirement communities (NORCs).

\footnotetext{
Quinn is with the The New York Academy of Medicine, New York, NY, USA.

Correspondence: Andrew Quinn, The New York Academy of Medicine, 1216 Fifth Avenue, New York, NY 10029, USA. (E-mail: aquinn@nyam.org)
} 
NORCs are communities where residents have grown older and remained in place, and new families have not displaced them. These communities can be contained within a single apartment building or be as large as an entire neighborhood. ${ }^{5,11}$ NORCs occur most often in urban areas and offer the immense psychological benefit of allowing older people to remain in their homes, an option the majority of older people prefer. ${ }^{5,12}$ Indeed, nearly nine in ten Americans over the age of 60 prefer to continue to live in their own neighborhoods. ${ }^{13}$ Residents of NORCs are also more likely to be involved in the community and have a greater number of friends in the neighborhood than other older populations. ${ }^{11}$ Because their social networks tend to be larger and densely associated around them, residents of NORCs have a greater number of people to rely on in times of emergency. At the same time, the social support they receive from neighborhood friends has been shown to positively influence their levels of physical activity. ${ }^{14-16}$ Their social networks can be more diverse than that of the older population in retirement communities because a diverse group of individuals and families can live in a NORC. As they evolve over time, NORCs are composed of a majority of older residents and a minority of younger newer families and individuals.

However, cities can also pose a number of threats to their older residents. Older adults who choose to remain in neighborhoods with a high prevalence of psychosocial hazards are more likely to be obese, regardless of age, gender, race/ ethnicity, education, wealth, alcohol consumption, and a host of other factors, than those who live in less hazardous neighborhoods. ${ }^{17}$ Many older people speak out about how, in neighborhoods of crime and violence, they feel afraid to leave their homes and walk around their neighborhoods. ${ }^{1}$ Research has explored their claims and found that older people are more likely than other groups to stay at home because of fear of crime and perceived lack of neighborhood safety. ${ }^{18-20}$ Those who are afraid of more mundane dangers, such as falling on broken sidewalks, reduce their outdoor physical activity. ${ }^{21}$ Despite these dangers, older people, by choice or by necessity, prefer to stay in their neighborhoods.

As they continue to age in place, social programs are needed to ensure that they age in good physical and mental health. In New York State, for example, social services, including nurses and case managers, have been financed by the state government in apartment buildings with high concentrations of residents more than $60 .^{13}$ Cities around the country could extend this program: first, by locating the NORCs within a municipality and then by using the healthy community checklists created by the AARP or the WHO to measure the quality of the needed services and improve them if need be. The New York Academy of Medicine has already taken the first step, in cooperation with the New York City Council, to assess the age-friendliness of New York City according to WHO standards. Such proactive developments will ensure a healthier older population while also improving their quality of life.

\section{ACKNOWLEDGMENTS}

Thanks to Alexandre Kalache and John Beard for helpful comments.

\section{REFERENCES}

1. WHO. Global Age-Friendly Cities: A guide. Available at: http://www who int/entity/ aging/publications/Global_age_friendly_cities_Guide_English pdf. Accessed November 28, 2007. 
2. United Nations. Population Aging 2006. Available at: http://www un org/esa/population/ publications/aging/aging2006 htm. Accessed November 28, 2007.

3. UN Habitat. Living Conditions of Low Income Older Persons in Human Settlements. Available at: http://ww2 unhabitat org/programmes/housingpolicy/pubvul asp. Accessed November 28, 2007.

4. WHO. New Guide on Building Age-Friendly Cities. Available at: http://www who int/ mediacentre/news/releases/2007/pr53/en/index html. Accessed November 28, 2007.

5. AARP. Beyond 50.05 A Report to the Nation on Livable Communities: Creating Environments for Successful Aging. Available at: http://assets aarp org/rgcenter/il/ beyond_50_communities pdf. Accessed November 28, 2007.

6. Tan EJ, Xue Q, Li T, Carlson MC, Fried LP. Volunteering: A physical activity intervention for older adults- The Experience Corps Program in Baltimore. J Urban Health. 2007;83 (5):954-69.

7. King WC, Belle SH, Brach JS, Simkin-Silverman LR, Soska T, Kriska AM. Objective measures of neighborhood environment and physical activity in older women. Am J Prev Med. 2005;28(5):461-9.

8. Li F, Fisher KJ, Brownson RC, Bosworth M. Multilevel modelling of built environment characteristics related to neighbourhood walking activity in older adults. J Epidemiol Community Health. 2005;59:558-64.

9. Patterson PK, Chapman NJ. Urban form and older residents' service use, walking, driving, quality of life, and neighborhood satisfaction. Am J Health Promot. 2004;19(1):45-52.

10. Booth ML, Owen N, Bauman A, Clavisi O, Leslie E. Social-cognitive and perceived environment influences associated with physical activity in older Australians. Prev Med. 2000;31(1):15-22.

11. Masotti P, Fick R, Johnson-Masotti A, MacLeod S. Healthy naturally occurring retirement communities: A low-cost approach to facilitating healthy aging. Am J Pub Health. 2007;96(7):1164-70.

12. Lagnado L. Old Notions: All-natural retirement isn't so easy, a look at the belnord showsin a luxury building, a duel between senior services and a landlord's vision-The symbolism of benches. The Wall Street Journal. July 3, 2001;A1.

13. Gross J. A Grass-roots effort to grow old at home. The New York Times. August 14, 2007.

14. Schutzer KA, Graves BS. Barriers and motivations to exercise in older adults. Prev Med. 2004;39(5):1056-61.

15. Walsh JM, Pressman AR, Cauley JA, Browner WS. Predictors of physical activity in community-dwelling elderly white women. J Gen Int Med. 2001;16(11):721-7.

16. Wilcox S, Castro C, King AC, Housemann R, Brownson RC. Determinants of leisure time physical activity in rural compared with urban older and ethnically diverse women in the United States. J Epidemiol Community Health. 2000;54(9):667-72.

17. Glass TA, Rasmussen MD, Schwartz BS. Neighborhoods and obesity in older adults: The Baltimore Memory Study. Am J Prev Med. 2006;31(6):455-63.

18. LaGrange R, Ferraro K, Supancic M. Perceived risk and fear of crime: Role of social and physical incivilities. J Res Crime Delinquency. 1992;29:311-34.

19. Centers for Disease Control and Prevention (CDC). Neighborhood safety and the prevalence of physical inactivitiy-Selected states, 1996. MMWR. 1999;48(7):143-6.

20. Wilcox S, Bopp M, Oberrecht L, Kammerman SK, McElmurray CT. Psychosocial and perceived environmental correlates of physical activity in rural and older African American and white women. J Gerontol B Psychol Sci Soc Sci. 2003;58(6):329-37.

21. Wijlhuizen GJ, Jong R, Hopman-Rock M, arijke. Older persons afraid of falling reduce physical activity to prevent outdoor falls. J Prev Med. 2007;44:260-4. 